\title{
EVALUASI HASIL HARDFACING ELEKTRODA HV 350 PASCA QUENCHING MEDIA AIR, COOLANT DAN OLI
}

\author{
${ }^{1)}$ Sopiyan, ${ }^{2)}$ Syamsuir \& ${ }^{3)}$ Yos Nofendri \\ 1)Program Studi Pendidikan Teknik Mesin, Fakultas Teknik, Universitas Negeri Jakarta \\ 2)Program Studi Teknik Mesin, Fakultas Teknik, Universitas Negeri Jakarta \\ 3)Program Studi Teknik Mesin, Fakultas Teknik, Universitas 17 Agustus 1945 Jakarta \\ E-mail: sopiyan@unj.ac.id
}

\begin{abstract}
Abstrak
Teknik hardfacing merupakan pengerasan permukaan dengan menambahkan unsur atau lapisan terertentu agar sifat logam induk menjadi lebih keras. Pada blade buldozer umumnya dikeraskan dengan memberikan lapisan hasil pengelasan dengan elektroda khusus. Elektroda tersebut memiliki sifat kekerasan yang tinggi, sehingga blade pada buldozer tidak cepat aus. Dalam penelitian ini akan dilakukan dua kali proses quenching. Pertama dengan menggunakan air ketika selesai proses pengelasan. Kemudian dilanjutkan dengan pemanasan kembali dalam tungku kemudian dilanjutkan dengan proses quenching dengan dua media yang berbeda yaitu oli dan coolant. Dari hasil yang penelitian didapatkan hasil kesimpulan, media coolant merupakan media yang paling optimal dalam meningkatkan kekerasan dari hasil hardfacing. Nilai kekerasan yang didapatkan dari hasil pencelupan dengan media coolant adalah sebesar 299,73 HV
\end{abstract}

Kata kunci: Hardfacing, HV 350, Quenching dan Kekerasan

\begin{abstract}
Hardfacing technique is surface hardening by adding certain elements or layers so that the nature of the parent metal becomes harder. On the bulldozer blade is generally hardened by giving a layer of welding results with special electrodes. The electrode has high hardness properties, so the blade of the bulldozer does not wear out quickly. In this research two quenching processes will be carried out. First by using water when the welding process is complete. Then proceed with reheating in the furnace then proceed with the process of quenching with two different media namely oil and coolant. From the results of the study concluded, coolant media is the most optimal media in increasing the hardness of the results of hardfacing. The hardness value obtained from the dyeing with coolant media is 299.73 $H V$
\end{abstract}

Keywords: Hardfacing, HV 350, Quenching and Hardness

\section{LATAR BELAKANG}

Teknik hardfacing merupakan pengerasan permukaan dengan menambahkan unsur atau lapisan tertentu agar sifat logam induk menjadi lebih keras. Pada blade buldozer umumnya dikeraskan dengan memberikan lapisan hasil pengelasan dengan elektroda khusus. Elektroda tersebut memiliki sifat kekerasan yang tinggi, sehingga blade pada buldozer tidak cepat aus (Lazić dkk, 2011). Dalam proses pengelasan tersebut hendaknya diperhatikan polaritas dan arus, karena hal ini penting untuk menghasilkan kekerasan tertentu (Mohruni, \& Kembaren, 2013). Ketika menggunakan arus yang terlalu tinggi akan menyebabkan cacat undercut dan spatter (Perdana, \& Syarif, 2015). Sehingga diperlukan arus yang tepat agar tidak terjadi cacat dalam proses hardfacing dengan pengelasan. Pada penelitian sebelumnya arus 110 dan 130A merupakan arus yang tepat, karena welder merasa nyaman saat proses pengelasan dengan hasil kekerasan diatas 
200 HV (Sopiyan dkk, 2018). Untuk lebih meningkatkan kekerasan dapat juga dilakukan proses pendinginan cepat (quenching) (Dwiyati dkk, 2018). Proses ini akan menghasilkan kekerasan sesuai yang diinginkan dengan menggunakan media pendingin yang tepat. Pada sektor manufaktur, media pendingin yang umum digunakan adalah oli. Namun pada beberapa penelitian bisa juga menggunakan media pendingin yang lain seperti air, udara dan coolant (Basori, 2018). Dalam penelitian ini akan dilakukan dua kali proses quenching. Pertama dengan menggunakan air ketika selesai proses pengelasan. Kemudian dilanjutkan dengan pemanasan kembali dalam tungku kemudian dilanjutkan dengan proses quenching dengan dua media yang berbeda yaitu oli dan coolant.

\section{METODOLOGI PENELITIAN}

Proses hardfacing menggunakan elektroda HV 350 dengan SMAW polaritas DC+ dan arus 110A. Setelah selesai pengelasan kemudian spesimen langsung dicelup air. Spesimen di panaskan kembali dalam furnace $1000^{\circ} \mathrm{C}$ selama 10 menit kemudian diquenching dalam oli dan coolant. Alur proses penelitian dapat dilihat pada diagram di bawah

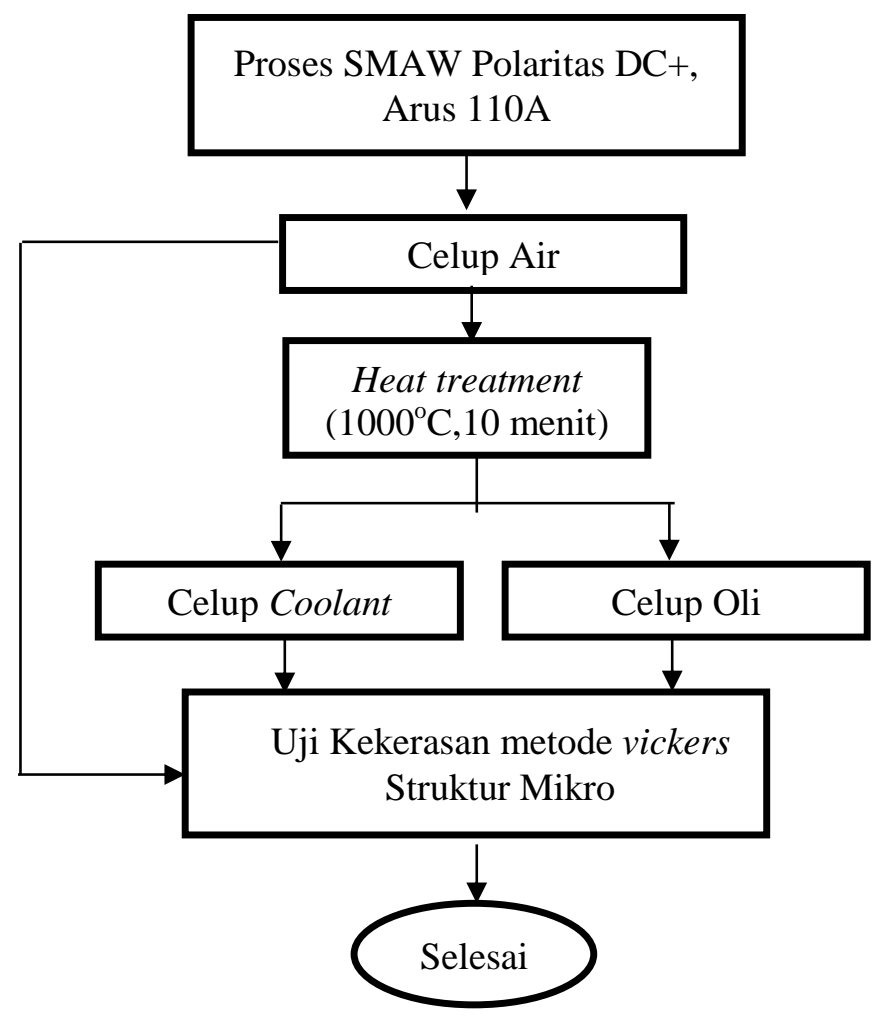

Gambar 1. Diagram Alir Penelitian

\section{HASIL PENELITIAN}

\subsection{Hasil Uji Kekerasan metode vickers}

Tabel 1 menunjukkan hasil uji kekerasan berbagai variasi dari media pendingin yang digunakan. 
Tabel 1. Rata - Rata Nilai Kekerasan Hasil Uji Keras Vickers

\begin{tabular}{|c|c|c|c|c|}
\hline No & Celup & Identasi & Kekerasan (HV) & Rata-Rata Kekerasan (HV) \\
\hline \multirow{4}{*}{1} & \multirow{3}{*}{ Air } & 1 & 205.4 & \multirow{3}{*}{222.03} \\
\hline & & 2 & 227.9 & \\
\hline & & 3 & 232.8 & \\
\hline & & 1 & 305.5 & \multirow{3}{*}{299.73} \\
\hline \multirow[t]{3}{*}{2} & Coolant & 2 & 303.4 & \\
\hline & & 3 & 290.3 & \\
\hline & & 1 & 208.4 & \multirow{3}{*}{236.37} \\
\hline \multirow[t]{2}{*}{3} & Oli & 2 & 243.4 & \\
\hline & & 3 & 257.3 & \\
\hline
\end{tabular}

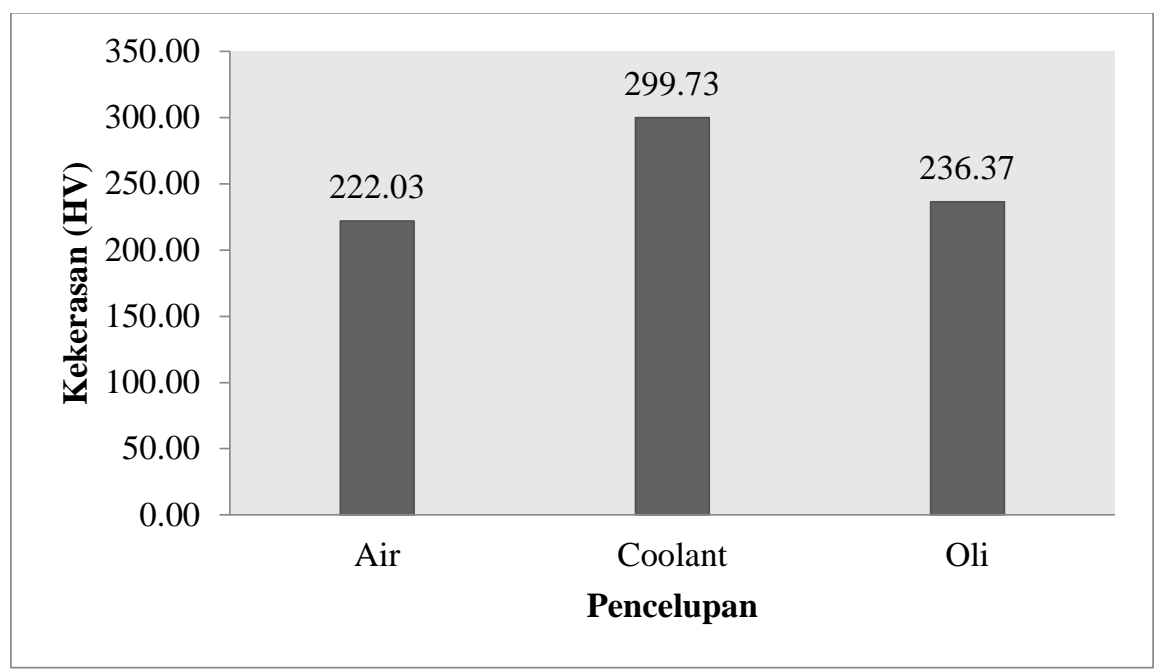

Gambar 2. Grafik Rata - Rata Nilai Kekerasan Hasil Uji Keras Vickers

Dari gambar 2 di atas yaitu grafik yang menunjukan rata - rata nilai kekerasan (HV). Terlihat nilai kekerasan dari suatu material akan lebih tinggi setelah dilakukannya pencelupan dengan air, coolant maupun oli sebagai media quenching.

Nilai kekerasan yang didapatkan tertinggi melalui uji kekerasan vickers adalah 299,73 HV dengan coolant sebagai media pendinginnya, kemudian kedua adalah 236,37 HV dengan oli sebagai media pendinginnya setelah sebeulmnya dilakukan quenching dengan media air.

\subsection{Hasil Pengamatan Mikroskop Optik}

Gambar 3. merupakan hasil pengamatan dengan mikroskop optik dengan perbesaran 50 kali.

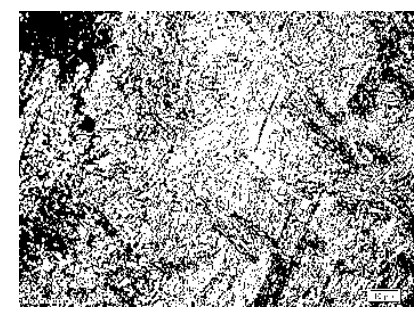

A

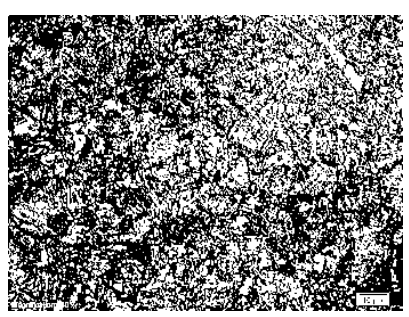

B

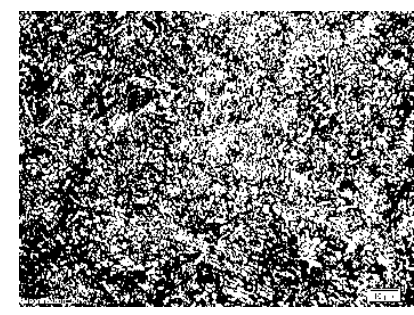

C

Gambar 3. Pengamatan dengan mikroskop optik dengan perbesaran 50 kali. (A) Celup Air (B) Celup Coolant (C) Celup Oli 
Dari struktur mikro pada gambar 3 merupakan struktur mikro pada deposit las dengan elektroda HV 350. Hasil menunjukkan foto yang berbeda ketika di celupkan setelah dilakukan proses pemanasan. Setelah dilakukan proses pengelasan kemudian dilakukan proses pencelupan menghasilkan bentuk seperti gambar 3 (A). Material kemudian dipanaskan kembali dengan temperatur $1000{ }^{\circ} \mathrm{C}$ kemudian dicelup coolant dan Oli menghasilkan gambar 3 (B) dan (C).

\section{KESIMPULAN}

Dari hasil yang penelitian didapatkan hasil kesimpulan, setelah dilakukan quenching kedua dengan dua media pendingin yang berbeda, media coolant merupakan media yang paling optimal dalam meningkatkan kekerasan dari hasil hardfacing. Nilai kekerasan yang didapatkan dari hasil pencelupan dengan media coolant adalah sebesar 299,73 HV

\section{DAFTAR PUSTAKA}

Basori, B. (2018). Pengaruh Media Quenching terhadap Kekerasan dan Struktur Mikro Paska Hardfacing. Jurnal Kajian Teknik Mesin, 3(2), 66-72.

Dwiyati, S. T., Susetyo, F. B., \& Yudhantono, A. D. P. (2018). Pengaruh Laju Aliran Gas Terhadap Nilai Kekerasan Baja Karbon Rendah Hasil Hardfacing Dengan Proses GTAW. Jurnal Konversi Energi dan Manufaktur UNJ, 5(1), 1-6.

Lazić, V., Mutavdžić, M., Milosavljević, D., Aleksandrović, S., Nedeljković, B., Marinković, P., \& Čukić, R. (2011). Selection of the most appropriate technology of reparatory hard facing of working parts on universal construction machinery. Tribology in industry, 33(1), 18-27.

Mohruni, A. S., \& Kembaren, B. H. (2013). Pengaruh Variasi Kecepatan Dan Kuat Arus Terhadap Kekerasan, Tegangan Tarik, Struktur Mikro Baja Karbon Rendah Dengan Elektroda E6013. Jurnal Rekayasa Mesin Universitas Sriwijaya, 13(1), 1-8.

Perdana, D., \& Syarif, A. B. (2015). Analisa Pengaruh Jenis Pengelasan SMAW Dan FCAW Terhadap Sifat Mekanis Baja ASTM A36 Pada Konstruksi Landside Upper Leg. ReTII.

Sopiyan, S., Susetyo, F. B., \& Syamsuir, S. (2018). Pengaruh Arus terhadap Kenyamanan Welder, Cacat Las dan Kekerasan Hasil Hardfacing Baja Karbon. Jurnal Kajian Teknik Mesin, 3(2), 83-88. 